Vol. 12, N. 1, Year 2020

ISSN: 2037-0830 - DOI: 10.2478/rem-2020-0003

\title{
Artificial Intelligence in Education and Schools
}

\author{
Ahmet Gocen, ${ }^{\mathrm{a}}$ Fatih Aydemir ${ }^{\mathrm{b}}$ \\ ${ }^{a}$ Harran University, Turkey,agocen@harran.edu.tr, https://orcid.org/0000-0002-9376-2084 \\ ${ }^{b}$ Ministry of National Education,Turkeyf.fatih.aydemir@gmail.com, https://orcid.org/0000-0002-9863-5842
}

\begin{abstract}
With the increase in studies about artificial intelligence (AI) in the educational field, many scholars in the field believe that the role of teachers, school and leaders in education will change. In this regard, the purpose of this study is to examine what possible scenarios are there with the arrival of AI in education and what kind of implications it can reveal for future of schools. The research was designed as a phenomenological study, a qualitative research method, in which the opinions of participants from different sectors were examined. The results show that schools and teachers will have new products, benefits and also face drawbacks with the arrival of AI in education. The findings point out some suggestions for use of AI and prevention of possible problems. While participants generally seem to have positive perceptions towards AI, there are also certain drawbacks, especially highlighted by teachers and academicians, regarding the future of teaching. Lawyers and jurists tend to focus more on legal grounds for AI in education and future problems, while engineers see AI as a tool to bring quality and benefit for all in the education sector.
\end{abstract}

Keywords: Artificial intelligence; education; school management

\section{Introduction}

Artificial intelligence (AI), generally expressed by the general public as the ability of machines or computers to think and act as humans do, represents the efforts towards computerized systems to imitate the human mind and actions (Wartman \& Combs, 2018). In this respect, the basic definition of artificial intelligence can be expressed as the skilful imitation of human behaviour or mind by tools or programs (Mohammed \& Watson, 2019). According to Timms (2016), it may be an illusion of the current structure to think that artificial intelligence will come within the computer format used at home. It could get into our lives within different functions and shapes.

$\mathrm{Ng}$ (2017) claims artificial intelligence to be the new electricity of this age. Artificial intelligence is a candidate to be presented as the basic building block of the Fifth Industrial Revolution by providing itself to be a powerful factor in ensuring economic development with its potential (see, Golic, 2019). That could be why investments in artificial intelligence broke a record in China with $\$ 40$ billion in 2017 (Mou, 2019). In line with its earnings from AI, China is expected to increase its gross domestic product (GDP) by $26 \%$ ( $\$ 7$ trillion) by 2030 . North America is expected to have a 14.5\% increase (\$ 3.7 trillion) in the same timeframe ( $\mathrm{PwC}$, 2017). These data make the added value and global impact of artificial intelligence more understandable for the future economy, and in our case, for the future of education, which in turn, directs the economy and workforce, paving the way for the new Industrial Revolution.

The in-depth development of artificial intelligence will affect many situations, from the restructuring of the social order in the broadest sense to the education and administration processes in classes and schools. Schools that are expected to adapt to the digital age and embed 21st century skills in their main agendas are some of the main institutions that could be most affected by the development of artificial intelligence. Karsenti (2019) points out that new forms of technology will fill in our lives and captivate our youth, and this case may leave schools with no choice but to make room for them. In this regard, how the stakeholders from law, business, education, and engineering perceive this development, and how they foresee artificial intelligence in regard to education form the focus of this study. Thus, the purpose of this study is to examine what the use of artificial intelligence in education means and what kind of implication it can reveal for the future of education, according to the opinions of the participants from different sectors. 


\subsection{Artificial Intelligence in Education}

Roll and Wylie (2016) highlight Henry Ford's quote, 'If I had asked people what they wanted; they would have said faster horses.' On the surface, it can be said schools have become 'faster classes' that produce results in a shorter time. But, will these 'fast classes' continue to do so or require thinking differently in the 21 st century? As we go towards the 22nd century, is it sufficient to provide skills, critical thinking, and metacognition skills? Or should we configure new systems that have never been thought of before for the new age? What opportunities can artificial intelligence offer in education that will differentiate people from robots or smart vehicles and help humans keep their emotional and social aspects? Most probably soon, these topics will be the main agenda of policymakers and implementors in the field; actually, there are already discussions asking if AI can truly replace teachers or not (see, Felix, 2020).

Manyika et al. (2017) emphasize that good teachers will continue to exist in the future, teaching classes designed to boost students' affective intelligence, creativity, and communication. In fact, according to these authors, developments in artificial intelligence and automation will actually make 'people more human.' While addressing educational research on artificial intelligence, Haseski (2019) briefly states the results of these studies as follows: the use of artificial intelligence in education will make learning more individual, provide effective learning experiences, enable students to discover their talents, improve their creativity and reduce teachers' workload. That being said, there are opposite ideas as well. Transferring the roles of teachers to computers is seen as a danger in the studies on artificial intelligence (Humble \& Mozelius, 2019). To prepare for this future, the task of states and nations is to create a teacher profile that will work with these support structures (Wogu, Misra, Olu-Owolabi, Assibong \& Udoh, 2018).

Although artificial intelligence studies in education have attracted a lot of attention in recent times, studies about the theory of general artificial intelligence can be traced back to at least the 14th century, and these studies remerged through the work of Alan Turing in 1937 (Humble \& Mozelius, 2019). They are now becoming an important point of academic literature and scientific circles. We see extension of AI studies in organizational management as 'artificial intelligence leadership' has begun to be discussed in the literature (see, Canbek, 2020).

With more usage of artificial intelligence in education, major transformations can be foreseen in the education systems and its processes. Based on the study results, Sekeroglu, Dimililer and Tuncal (2019) stated that artificial intelligence could help teachers improve personalized education for their students. Artificial intelligence can provide access to appropriate and better learning opportunities for excluded people and communities, people with disabilities, refugees, people out of school, and those living in isolated communities (Pedro, Subosa, Rivas, \& Valverde, 2019). Research shows how effective individually tailored approaches can be presented with the support of artificial intelligence techniques and intelligent learning environments (Mohammed \& Watson, 2019). Although quality education seems to require the active participation of human teachers, artificial intelligence envisages increasing education and quality at all levels, especially by providing personalization (Grosz \& Stone, 2018). Pedro et al. (2019) highlight a dual-teacher model with artificial intelligence in terms of individualized education: teachers spend a lot of time in routine and other administrative tasks, such as repeating frequently, answering questions about many topics, but in-class artificial intelligence-supported assistants (secondary teachers) will reduce the time spent on routine procedures, which will help teachers focus on student guidance and one-to-one communication.

\section{Research Method}

The research was designed as a phenomenological study, which is a qualitative research method. Qualitative research is preferred when it is desired to examine a problem or subject in depth (Creswell, 2013). Research with the aim of uncovering the ideas and the meanings of individuals is called phenomenological research (Yildirim \& Simsek, 2008). Thus, we tried to uncover the opinions of the participants in regard to the AI in education. In this study, where the perceptions of the participants on artificial intelligence in education from four different professions were examined, a triangulated data collection was considered.

\subsection{Participants}

Purposeful sampling was preferred during the determination of the participants. Purposeful sampling is the selection of a data-rich sample in accordance with the purpose of the research (Buyukozturk, Cakmak, Akgun, Karadeniz \& Demirel, 2018). Four target groups that include 19 persons in total have been identified by researchers regarding artificial intelligence in education:

- Academicians; academics working in the field of educational sciences (5 people)

- Legal Experts; lawyers and judges currently working in courts (5 people)

- Experts; technical experts on artificial intelligence (4 people), in private or public organizations 
- $\quad$ Teachers; teachers currently working (5 people) in public schools

The results were reported using tag names to keep the names of the participants confidential. Names determined were as follows: Ahmet, Ayşe, Fatma, Hatice, Emine, Ali, Huseyin, Ismail, Suleyman, Tahsin, Kemal, Elif, Kubra, Mahmut, Burak, Mehmet, Ziya, Recep, Esref.

\subsection{Collection of Data and Analysis}

Semi-structured interviews were employed in the study. The questions sent online to the participants included 'what they think of AI, how it will be integrated into education, the future outlook, the positive and negative implications they have on AI in education' along with additional questions. With the answers to the above questions, participants' perceptions of the use of artificial intelligence in education were analysed.

Questions to examine participants' opinions within the research were prepared by taking the opinions of three experts in the field of educational sciences. The questions were first sent to the participants in an online form and filled in. Later, to get more detailed information on the subject, face-to-face interviews were held with the participants about what they wrote in the form. In the first data collection, the participants were assumed to express themselves better alone in writing, while in the second voluntary face-to-face meeting, the researchers revealed the points needed more clarification as assumed by the researchers.

All the data were analysed according to the content analysis method from codes to more holistic themes. The aim here is to examine the data collected from all the participants line by line. First, codes were formed, leading to themes, which are ultimately comparable to the literature. In each coding stage and in determining the themes, all the lines were taken into consideration. In the findings part, more explanation was given to the codes highlighted in the analysis (e.g., individualization of instruction). The participants' views on AI are investigated within their existing experience and understanding of AI with possible scenarios in their minds. Only one question (the last question) was coded with a predetermined numerical format, as shown in Table 1.

\subsection{Trustworthiness}

In qualitative research, trustworthiness bears a paramount importance. To employ a more trustworthy process in the study, the data collection, coding, tabulation and reporting stages of qualitative research are followed by an expert academician in the field. In addition, the researchers stated their preliminary assumptions regarding the subject. Preliminary judgments of participants were asked. There was a comprehensive analysis independent of three academicians: an analyst triangulation. The data source triangulation method (Streubert \& Carpenter, 2011) was used.

We also tried to examine many different studies on AI from health to industry to enable perspective triangulation. Triangulation means the use of multiple methods or data sources in qualitative research in developing a comprehensive understanding of cases or phenomena (Patton, 1999). The participation of experts from different fields in the study on artificial intelligence in education provided a rich and different data source. The compatibility of the data with similar studies in the literature was examined in detail. A content comparison was done by providing data and results from multiple data sources. The researchers' prejudices were minimized. Raw data and analysed versions are retained for possible controls later. The working process, purpose and methods were clearly stated to the participants. The participants and the process were explained in detail regarding transferability. They were informed about ethical codes, and they were told that they could quit the study any time they want.

\section{Findings}

The main themes obtained in this section are built on the codes most emphasized by the participants. The codes specified within the scope of the themes are not sorted according to any frequency value; however, the most highlighted ones are given with their explanation below. Upon participants' consent, the codes and expressions in the final findings are seen to be confirmed by participants with different specialties. When the data was analysed, it was first seen that the participants firstly emphasized the products, applications, and outputs that will enter our lives with the arrival of artificial intelligence, and all other themes are explained below. Since participants touched upon many aspects under products, drawbacks, benefits, suggestions, we tried to give a few general quotations under each dimension that covers the theme.

\subsection{Products (Outcomes)}


Under this theme, the products and solid outcomes expected in the education sector by the participants were seen to be expressed. Under the products dimension, we listed the possible products and outcomes they expect in education. The scope of products included not only tangible tools, but also software, systems, methods and models. The products that would stand out or might hold a prominent place in education with artificial intelligence can be listed as follows:

- Advanced technology software

- Robot assistants and robot teachers

- Smart classes in schools

- Individualized education (pertains to individualization of instruction)

- Simulations for education and lessons

- Scenario and case study-producing systems

- Interest, ability, and needs analysis systems

- Vocational guidance system (for career choice)

- Programs or tools for taking attendance

- Unmanned systems of all sorts

- Learning outcome detection system (for levels of students)

- Personal teaching tools

- Attention and distraction analysis system

- Academic success detection and suggestion system for improvement

- Learning systems in cloud environments and virtual learning environments

- Curriculum editing system

- Systems that perceive and report students' learning patterns

Supporting products/outcomes theme, one participant, Tahsin (an academician), told us, 'Artificial intelligence in education can be used in many areas from individual learning, examination opportunities, face recognition system to taking attendance at the entrance to the class. ' and highlighted tools for the personalization of learning. Similarly, Ziya (a lawyer) mentioned, 'Providing individualized education by virtualizing teaching through artificial intelligence.' Moreover, Mahmut (an expert engineer) stated, '...Curriculum planning can be left to artificial intelligence mechanisms[tools] by developing machine learning algorithms related to the educational system.'

\subsection{Drawbacks}

In this theme, the possible drawbacks and risks about the use of artificial intelligence in education were mentioned. These drawbacks, according to the participants, can be listed as follows:

- Mechanical thinking of individuals, suppressing intuitive knowledge

- The humanistic values could be replaced by a utilitarian or pragmatic perspective,

- The possible bad scenarios with the full evaluation of students, categorization of humans based on their IQ, etc.

- The information-oriented human type,

- No need for human intervention in education,

- The possibility of uncontrolled intelligence technologies in education (e.g., data security),

- Negative effects on social relationships.

Participants separately mentioned possible risks and drawbacks in the interviews. There are expected risks, especially among teacher participants. Ayşe (a teacher) believes, "Artificial intelligence will increase its dominance over the world [Not much need for human intervention]." Ali (an academician) said, "[some sort of] machine-human style, mechanicalthinking individuals are waiting for us." Emine (a teacher) states, "I think that we will not need teachers in the distant future." Burak (a jurist) also bears the same ideas of teachers, stating, "Artificial intelligence will take over all educational tasks; even a teacher may not be needed." Among the possible causes of these concerns are the effects of dystopic robot films and popular media, which some participants believed could come true.

\subsection{Benefits}

In this theme, the results obtained from the opinions of the participants about the benefits of using artificial intelligence in education are presented. Accordingly, these benefits are:

- People measurement or measuring people 


\section{Artificial Intelligence in Education and Schools}

Gocen, Aydemir

- Helping individual at learning at their own speed

- Correct determination of the individual's need

- Practical solutions to chronic problems

- No more paperwork in schools

- Prevention of waste of time

- Increase in education quality

- Providing ease of work

- Helping the right decisions with fast data analysis

- Planning teaching according to student capacity and speed

- Using or choosing effective learning methods using a learning analysis

- Ability to train in smaller groups with effective planning

- More effective individual learning process

- Helping policymakers, for example, population prediction simulations for making the right education investments in the right places

İsmail (an academician) asserted, '... As a benefit of artificial intelligence, the student's information can be monitored, evaluated, and planning can be made about which profession that this student should focus on in the future.' Another participant, Elif (an expert engineer) told the researchers, '...regular reporting of students' situation at school, creating suggestions according to these reports and sharing with relevant people...' Esref (a jurist), said, 'Artificial intelligence tools can assist in evaluating the results of exams, student movements, and communication between students.' Ahmet (a teacher) stated, 'An AI tool can analyze [sic] the voice of students and measure how much they have learned and offer supportive or regulatory directives accordingly.' These ideas of participants are closely related to the benefits that could stem from 'learning analytics' in the literature.

\subsection{Suggestions}

This theme included the participants' suggestions regarding the use of artificial intelligence in education. These recommendations are as follows:

- There should be a certain measurement system when using artificial intelligence in education.

- Applications or systems developed regarding artificial intelligence in education should be tested with pilot applications and integrated into the system according to their results.

- Academic studies should be done on the developed systems and analysed.

- Necessary infrastructure works should be created.

- An audit mechanism should be established.

- Human psychology should not be ignored.

- Preventive and supportive software should be developed.

- The effects of artificial intelligence-related systems on the decision-making power of people in their lives should be measured.

- The AI integration process should proceed in a way that does not affect social relations negatively.

- Artificial intelligence in education is not a comprehensive solution; it should be used only in the areas of need.

- The process should be carried out in an interdisciplinary fashion with all stakeholders, not just educators and engineers.

To this point, Hatice (a teacher) said, 'A conscious use of artificial intelligence must be present; AI should be preferred only for the areas that are needed.' Ali (an academician) said, 'We need to be careful in taking steps. Academic studies can be done. It is important to run pilot applications.' Kubra (an expert engineer) explained the general outline as follows: 'Artificial intelligence should not be at the center [sic] of educational activities; it should act as a helping element, play a supporting role for teachers and the human factor. In order to eliminate risks, AI systems should be fully linked to human control.'

Since it is humanity that is most affected by technology, it is important that this entire process is carried out on a legal basis so as not to harm anyone. Recep (a lawyer) said, 'If it can be based on a legal legislation, the drawbacks can be minimized.' In regard to legal cases, Mehmet (a jurist) stated his ideas on data privacy: 'The storage, protection, and confidentiality of personal data in coming AI systems must be essential; individuals are particularly concerned with mental analysis, and a measurement of persons will lead an entire life to be exposed. This issue should be addressed in two stages: 1- To establish the necessary infrastructure for the state to fulfil this obligation, to give access to the related body through strict protocols. 2- To prevent the violation of confidentiality, to eliminate this violation with the fastest and the least damage, states should apply deterrent penalties." 
The last questions posed to the participants included a descriptive aspect: How do you define AI tools in education when artificial intelligence-supported educational environments are considered?... 'please give us a clear percent if AI is beneficial or problematic?' By giving a percentage, participants gave answers about how much harm and benefit they foresee in the integration of AI with education and society; they both focused on benefits and drawbacks. The distribution of the answers given to this question by the groups is shown in Table 1.

Table 1. Distribution of benefit - drawback percentages by groups

\begin{tabular}{llc}
\hline Groups & Benefit Average & Drawback Average \\
\hline Academicians & $\% 56.00$ & $\% 44.00$ \\
Law Personnel & $\% 72.20$ & $\% 27.80$ \\
Expert Engineers & $\% 95.00$ & $\% 5.00$ \\
Teachers & $\% 62.00$ & $\% 38.00$ \\
General & $\% 68.67$ & $\% 31.33$ \\
\hline
\end{tabular}

In this respect, it can be said that the participants generally viewed AI developments positively. Academicians may have evaluated the possible benefits and harms of teaching solely in terms of teaching professions and may have seen possible problems in the teachers' future, while they seem to accept the benefits in teaching processes. Expert engineers, on the other hand, stated that in terms of systems, AI would bring quality and benefit for all in the education sector.

\section{Conclusions}

The interviews with the participants produced four main themes and one descriptive theme on AI in education. The first theme was about the products, which included solid AI media, applications, or outcomes in the near future. These ranged from simulation programs, evaluation-testing support systems, VR class and assistant robots to personalized learning systems. One of the most concurrent topics on AI as an imminent outcome is its impact on personalized learning with the tools it provides. Artificial intelligence in education can provide strong technical support for personalized learning (Chang \& Lu, 2019). Goksel and Bozkurt (2019), upon their analysis of papers on education and AI studies, found adaptive learning, personalization and learning styles as the central key nodes and concepts. This means that adopting a one-size-fits-all approach can be replaced by the use of AI in education with tailored learning for each student. So, we can infer that progress in education can fulfil the requirements of optimum learning with AI and its supporting tools, being a huge help in assisting teachers and students. Abdelsalam, (2014) in this regard, proposed an intelligent tutoring system (ITS) based on mastery learning strategy.

The second theme was about the drawbacks and risks. Participants in the study believed that a pervasive use of AI would lead to an overly mechanical way of information processing, pragmatic approach, much focus on the knowledge rather than the aesthetic feelings, lesser room for teachers, ethical and security-related problems, and negative social effects in relationships. In the existing case, the uncontrolled, inappropriate or excessive use of the mobile phone already seems to cause behavioural, social and affective problems (Choliz, 2010). This may be deepened with the unconscious integration of AI into the human life and phones as participants noted that mobile devices already stripped people of their social interactions, and they really wonder about the next step with AI development in the mobile world.

The participants think there will be fewer places for teachers in schools and more places for robot assistants. Parallel to those observations, Picciano (2019) asserts that the majority of people with displaced jobs will be in white-collar and professional areas, such as teaching, law, medicine and the corporate sector. One of the fears most faced in the community about AI is the elimination of jobs. Picciano (2019) also hints that it is not AI or machines that will replace human work; rather, it is people with the ability to use smart machines or intelligent systems that will overpower those who do not. Roll and Wylie (2016), writing about the role of teachers, assert that teaching in existing context will not stay same any longer; thus, teachers should assume the roles of mentors, teaching their students lifelong skills, interaction, going out of the normal zone, and focusing on life problems.

Even though we have not reached the level of artificial intelligence that TV programs portray, the development of artificial intelligence is accelerating. A common point in the comments of the participants, either as a result of movies or a fear of smart tools in the community, is related to Isaac Asimov's book I, Robot, and the adapted film. Some participants mentioned robot laws by Isaac Asimov, which can be given as below (Asimov, 2004):

1. A robot may not injure a human being or, through inaction, allow a human being to come to harm, except when required to do so in order to prevent greater harm to humanity itself.

2. A robot must obey any orders given to it by human beings, except where such orders would conflict with the First Law or cause greater harm to humanity itself.

3. A robot must protect its own existence as long as such protection does not conflict with the First or Second Law or cause greater harm to humanity itself. 


\title{
Artificial Intelligence in Education and Schools
}

\author{
Gocen, Aydemir
}

Later, a zeroth law was introduced:

0 . A robot may not harm humanity, or by inaction, allow humanity to come to harm.

One of the prominent emphases on preventing risk against artificial intelligence technologies is 'proportionality.' To this point, participants told academics, engineers and related professionals should follow a conscious use of artificial intelligence and related tools.

The third theme was about the benefits incurred by AI. This theme is similar to the first theme under solid outcomes but differs in that this theme is focused on functions and uses. The participants in the study believe that AI-empowered systems will help content to keep pace with the speed of the learner, help systems to better determine the needs of learners, end the waste of time and resources, enable fast data analysis, and empower the right decisions. For example, one of the participants found AI very helpful in that it can lead States to invest in related areas by predicting the movements of populations. Subrahmanyam and Swathi (2018) mention that using AI-enabled predictive computing could learn students' habits and propose the most efficient study schedule for them. Roll and Wylie (2016) assert that students and teachers are in need of better, personalized support; thus, AI will better address the needs of learners and help students learn at their own pace. Subrahmanyam and Swathi (2018) also tell the benefit of AI in education as guiding students in mastery, repeating lessons as needed, and quickly designing a personalized learning plan for each student.

The ideas of some participants are closely related to the concept of 'learning analytics' in the literature. Learning analytics is defined as the collection, measurement, analysis and reporting of the information about learners and their context to understand and improve learning and its environments (Long \& Siemens, 2011). With the increase of artificial intelligence technologies in education, learning analytics can also contribute to the provision of individualized learning content. From this point of view, the spread of artificial intelligence technologies in education is important for the formation of a flexible, editable curriculum. The function of learning analytics holds a prominent place as an important function of AI applications. One participant mentioned one outcome of the AI as 'measurable persons,' which meant that AI would analyse people and produce predictions to make the progress of students and teachers better, similar to learning analytics. In this regard, Karsenti (2019) states that with the support of analyses based on artificial intelligence tools, even school absenteeism rates will decrease, a huge benefit for schools.

The fourth theme includes suggestions from participants who proposed precautionary models, supervised systems, and pre-analysed steps for AI integration into the educational field. There should be several types of supervision on the technical and judiciary levels. Participants advocated that the inclusion of AI into personal matters should be limited. AI in education should not to be assumed as an answer for all, but a media that simplifies and tightens up processes in necessary areas. Otherwise, artificial intelligence technologies, based on the imitation of human intelligence, may bring legal problems. Some of these problems can be listed as to whom AI will report, what responsibility these tools will have, the property rights of the products produced by artificial intelligence, privacy and security issues. At this point, the legal ground should be adapted to the technological developments, and special laws regarding AI tools should be shaped according to robots or teacher assistants in the expected future.

AI for education includes excitement and promising developments for schools. It is important to manage the new developments by carefully discussing the context and effects. Artificial intelligence technologies are an exciting area for humankind; however, as the participants in this research have implied, it is not a cure for everything or an improvement that will bring absolute good. Therefore, the legal, ethical, pedagogical, psychological and sociological harms and benefits are to be considered. Since it is humanity that is most affected by technology, it is important that this entire process is carried out on a legal basis, so as not to harm anyone.

The fifth outcome within this study is the generally positive outlook concerning AI. Most of the participants seem to have positive views about AI. While teachers in the study see AI as beneficial for education, academicians seem to agree less with this idea and focus on more negative aspects. Experts in the field consider AI systems as beneficial since these systems will likely lead to full performance and remove problems in the systems, easing human labour. The general positive and negative outlook seems to stem from media, films, expert knowledge, fear about future teaching professions and actual experience with existing online systems.

Lastly, this study was completed with the participation of different professionals, which presented a comprehensive educational stakeholder perception about artificial intelligence in education and schools. The data obtained from the study exhibits four main themes: a) Products: the emergence of possible products/solid outcomes with the use of artificial intelligence in education; b) Drawbacks: the possible drawbacks with the use of artificial intelligence in education; c) Benefits: the anticipated benefits with the use of artificial intelligence in education; d) Suggestions: the suggestions on the use of artificial intelligence in education. Surely, there will be associated benefits, drawbacks and risks for schools with the arrival of AI into schools. Most of the participants believe AI will open up new opportunities for students and learners, which normal classroom or educational tools may not deliver. But, there could also be problems. Schools need a proactive approach for their roles before the next industrial revolution. Policymakers should follow the suggestions in the literature for incurring the benefits of AI in educational field. 


\section{Artificial Intelligence in Education and Schools}

Gocen, Aydemir

\section{Acknowledgement}

This study was supported within the project named Artificial Intelligence Education for Children (2019-1-TR01-KA20107704) by the Erasmus+ Programme of the European Union. European Commission and Turkish National Agency cannot be held responsible for any use which may be made of the information contained therein.

\section{References}

Abdelsalam, U. M. (2014, March). A proposal model of developing intelligent tutoring systems based on mastery learning. Paper presented the Third International Conference on E-Learning in Education (pp. 106-118). Retrieved from http://paper.researchbib.com/view/paper/14102

Asimov, I. (2004). I, Robot. New York: Bantam Books.

Buyukozturk, S., Cakmak, E. K., Akgun, O. E., Karadeniz, S., \& Demirel, F. (2018). Bilimsel araştırma yöntemleri [Scientific research methods]. Ankara: Pegem A Yayınc1lı.

Canbek, M. (2020). Artificial Intelligence Leadership: Imitating Mintzberg's Managerial Roles. In Business Management and Communication Perspectives in Industry 4.0 (pp. 173-187). IGI Global.

Chang, J., \& Lu, X. (2019, August). The study on students' participation in personalized learning under the background of artificial intelligence. In 10th International Conference on Information Technology in Medicine and Education (ITME) (pp. 555-558). IEEE.

Choliz, M. (2010). Mobile phone addiction: a point of issue. Addiction, 105(2), pp. 373-374.

Creswell, J. W. (2013). Qualitative inquiry and research design: Choosing among five approaches, SAGE publications

Felix, C.V. (2020). The Role of the Teacher and AI in Education. Sengupta, E., Blessinger, P. and Makhanya, M.S. (Ed.) International Perspectives on the Role of Technology in Humanizing Higher Education (Innovations in Higher Education Teaching and Learning, Vol. 33), Emerald Publishing Limited, pp. 33-48. https://doi.org/10.1108/S2055$\underline{364120200000033003}$

Goksel, N., \& Bozkurt, A. (2019). Artificial intelligence in education: current insights and future perspectives. In S. Sisman-Ugur \& G. Kurubacak (Eds.), Handbook of Research on Learning in the Age of Transhumanism (pp. 224236). Hershey, PA: IGI Global.

Grosz, B. J., \& Stone, P. (2018). A century-long commitment to assessing artificial intelligence and its impact on society. Communications of the ACM, 61(12), pp. 68-73.

Golic, Z. (2019). Finance and artificial intelligence: The fifth industrial revolution and its impact on the financial sector. Zbornik radova Ekonomskog fakulteta u Istočnom Sarajevu, (19), pp. 67-81.

Haseski. H.I. (2019). What do Turkish pre-service teachers think about artificial intelligence? International Journal of Computer Science Education in Schools, 3(2), Doi: 10.21585/ijcses.v3i2.55

Humble, N., \& Mozelius, P. (2019, October). Artificial Intelligence in Education-a Promise, a Threat or a Hype?. In European Conference on the Impact of Artificial Intelligence and Robotics 2019 (ECIAIR 2019), Oxford, UK (pp. 149-156). Academic Conferences and Publishing International Limited.

Karsenti, T. (2019). Artificial intelligence in education: the urgent need to prepare teachers for tomorrow's schools. Formation et profession, 27(1), pp. 112-116. Doi:10.18162/fp.2019.a166.

Long, P., \& Siemens, G. (2011). Penetrating the fog: Analytics in learning and education. EDUCAUSE Review, 46(5), pp. 31-40.

Manyika, J., Chui, M., Miremadi, M., Bughin, J., George, K., Willmott, P., \& Dewhurst, M. (2017). A future that works: Automation, employment, and productivity. Chicago: McKinsey Global Institute.

Mohammed P.S., \& Watson E. N. (2019). Towards inclusive education in the age of artificial intelligence: perspectives, challenges, and opportunities. In: Knox J., Wang Y., Gallagher M. (eds) Artificial Intelligence and Inclusive Education. Perspectives on Rethinking and Reforming Education. Singapore: Springer. https://doi.org/10.1007/978981-13-8161-4 2

Mou, X. (2019). Artificial intelligence: investment trends and selected industry uses. EMCompass; No. 71. Washington, D.C.: World Bank Group.

$\mathrm{Ng}$, A. (2017, January 25). Artificial intelligence is the new electricity. Speech presented at Stanford MSx Future Forum in California, Stanford. https://www.youtube.com/watch?v=21EiKfQYZXc.

Patton, M. Q. (1999). Enhancing the quality and credibility of qualitative analysis. Health services research, 34(5/2), pp. 1189-1208.

Pedro, F., Subosa, M., Rivas, A., \& Valverde, P. (2019). Artificial intelligence in education: Challenges and opportunities for sustainable development. Paris: UNESCO.

Picciano, A. (2019). Artificial intelligence and the academy's loss of purpose. Online Learning, 23(3), Doi:10.24059/olj.v23i3.2023

PwC. (2017). Sizing the prize What's the real value of AI for your business and how can you capitalise? Retrieved from https://www.pwc.com/gx/en/issues/analytics/assets/pwc-ai-analysis-sizing-the-prize-report.pdf. 
Roll, I., \& Wylie, R. (2016). Evolution and revolution in artificial intelligence in education. International Journal of Artificial Intelligence in Education, 26(2), pp. 582-599.

Sekeroglu, B., Dimililer, K., \& Tuncal, K. (2019). Artificial intelligence in education: application in student performance evaluation. Dilemas Contemporáneos: Educación, Política y Valores, 7(1), pp. 1-21.

Streubert, H. J., \& Carpenter, D. R. (2011). Qualitative research in nursing. (5 ${ }^{\text {th }}$ ed.). Philadelphia: Lippincott Williams and Wilkins.

Subrahmanyam, V. V., \& Swathi, K. (2018). Artificial intelligence and its implications in education. In Int. Conf. Improv. Access to Distance High. Educ. Focus Underserved Communities Uncovered Reg. Kakatiya University (pp. 1-11).

Timms, M. J. (2016). Letting artificial intelligence in education out of the box: educational cobots and smart classrooms. International Journal of Artificial Intelligence in Education, 26(2), pp. 701-712, Doi: 10.1007/s40593016-0095-y

Wartman, S. A., \& Combs, C. D. (2018). Medical education must move from the information age to the age of artificial intelligence. Academic Medicine, 93(8), pp. 1107-1109.

Wogu, I. A. P., Misra, S., Olu-Owolabi, E. F., Assibong, P. A.. \& Udoh, O. D. (2018). Artificial intelligence, artificial teachers and the fate of learners in the $21^{\text {st }}$ century education sector: Implications for theory and practice. International Journal of Pure and Applied Mathematics, 119(16), pp. 2245-2259.

Yildirim, A., \& Simsek, H. (2008). Sosyal bilimlerde nitel araştırma yontemleri [Qualitative research methods in the social sciences]. Ankara: Seckin Publication. 